\title{
A POLÍTICA ANTITRUSTE NO BRASIL E O COMBATE A CARTÉIS À LUZ DO NOVO CADE
}

\author{
THE ANTITRUST POLICY IN BRAZIL AND THE FIGHT AGAINST CARTELS \\ BASED ON THE NEW “CADE"
}

Erick Leonardo Freire Carvalho ${ }^{1}$

\begin{abstract}
RESUMO: O Conselho Administrativo de Defesa Econômica-CADE é uma autarquia federal que tem como objetivo a proteção da livre concorrência, um dos princípios constitucionais que norteiam a ordem econômica brasileira. Dentre as condutas anticompetitivas, o cartel é a mais grave lesão à concorrência, pois prejudica seriamente os consumidores ao aumentar preços e restringir a oferta, tornando os bens e serviços mais caros ou indisponíveis. $\mathrm{O}$ objetivo deste trabalho é analisar as consequências e procedimentos tomados para identificar e impor sanções à prática de cartel. Trata-se de uma pesquisa baseada em um levantamento bibliográfico complementado com pesquisa de campo no próprio CADE. Logo, pela observação dos aspectos mencionados, percebe-se que no campo prático, o Brasil considera o combate a cartéis uma prioridade absoluta e como reconhecimento de tal esforço, o Sistema Brasileiro de Defesa Econômica-SBDC é considerado, no âmbito internacional, como um órgão que tem se destacado nos últimos anos.
\end{abstract}

PALAVRAS-CHAVE: Conselho Administrativo de Defesa Econômica - CADE. Cartel. Direito Concorrencial. Lei n. 12.529/11. Lei Antitruste.

ABSTRACT: The Council for Economic Defence (CADE) is a government corporation whose purpose is protecting free competition, one of the constitutional principles that raise Brazilian Economy. Among all anticompetitive conducts, cartel is the most egregious violation of competition law, because it has a huge impact on consumers through getting the prices higher and limiting the supply, which becomes the goods and services more expensive or unavailable. This article aims to analyze the consequences and procedures used to identify and imposing penalties to cartel activity. This is an approach about the literature and field researches realized at CADE itself. Therefore, through the observation of mentioned aspects, it is possible to infer that Brazil considers combating cartels an absolute priority indeed and, as an acknowledgement of such effort, The Brazilian Competition Policy System (SBDC) has been detached worldwide in the last years.

KEYWORDS: The Council for Economic Defence (CADE) - Cartel - Competition Law - Law 12.529/11 - Antitrust Law.

\footnotetext{
${ }^{1}$ Aluno do do Curso de Direito da Faculdade Maurício de Nassau - FAP TERESINA. Participante do XXXIII Pincade. Pesquisador Iniciante no Núcleo Acadêmico de Pesquisas em Política, Estado e Direito "Cláudio Pacheco" - NAPPEDIC e Instituto de Pesquisa Maurício de Nassau - IPMN. E-mail: erickleonardofreire@ hotmail.com
} 


\section{INTRODUÇÃO}

Percebe-se que nas sociedades modernas o desenvolvimento sustentável destaca-se como a maior preocupação das políticas. No âmbito econômico, a defesa da competitividade é a ferramenta que permite a sustentabilidade dos mercados. As políticas antitrustes têm merecido reconhecimento internacional como um dos instrumentos de política econômica indispensáveis para garantir a competitividade das economias ${ }^{2}$.

A defesa da concorrência preocupa-se com o bom funcionamento do mercado. Ao se assegurar a livre concorrência, garantem-se não somente os preços mais baixos, mas também produtos de melhor qualidade, diversificação e inovação, aumentando, portanto, o bem estar do consumidor e o desenvolvimento econômico.

A livre concorrência é um dos princípios que norteiam a ordem econômica brasileira insculpido na Carta Magna pátria.

O Sistema Brasileiro de Defesa Econômica - SBDC é responsável pela promoção de uma economia competitiva, por meio da prevenção e da repressão de ações que possam limitar ou prejudicar a livre concorrência no Brasil, sendo sua atuação orientada pela Lei $\mathrm{n}^{\circ}$ 12.529, de 30 de novembro de 2011.

Neste contexto, a atuação do CADE no combate ao cartel será o objeto de análise do presente paper, buscar-se-á primeiramente, elucidar o contexto histórico-legislativo que instituiu a autarquia, a sua definição, assim como sua forma de atuação a partir da nova lei. Posteriormente, à luz da atual política antitruste, analisar-se-ão os esforços do CADE para identificar e impor sanções pela prática cartesiana, assim como a tipificação penal, sanções e classificação de tal conduta.

Diante de tantos questionamentos em relação à nova legislação Antitruste, e devido a pouca quantidade de bibliografia específica a respeito do combate ao cartel, é de suma importância a produção científica sobre o tema, através da qual, se venha alcançar uma conclusão objetiva, acerca do impacto da referida lei.

\footnotetext{
2 MONTEIRO, Carmen Diva. Sobre a política antitruste no Brasil e seus aspectos críticos. Dez. 2002. Disponível em: < http://www.seae.fazenda.gov.br/central_documentos/textos_artigos/2002-1/6antitrustpolicyininfrastructureservicesadevelopingcountryperspective>. Acesso em: 06. Jan. 2013.
} 
O artigo foi desenvolvido a partir de uma análise crítica do material bibliográfico e documental, associado à pesquisa direta na Coordenação de Cartel da Superintendência-Geral do CADE.

\section{BREVE LEVANTAMENTO HISTÓRICO DO DIREITO CONCORRENCIAL}

O Brasil possui um rico e peculiar histórico da política concorrencial. A era moderna da política antitruste iniciou-se nos anos 90, no contexto da transição do país para uma economia de mercado. Após a II Guerra Mundial, as políticas econômicas do Brasil foram caracterizadas pela profunda interferência estatal. Os preços eram controlados pelo Estado, e havia de certa forma uma cooperação entre as empresas privadas e o ente governamental. Em 1962 foi promulgada a primeira lei da concorrência no Brasil, trata da Lei $\mathrm{n}^{\circ}$ 4.1362/62, criou consequentemente o CADE, com a competência de eliminar o abuso do poder econômico que gere qualquer tipo de anticoncorrencialidade ${ }^{3}$.

Em 1990, o presidente promoveu uma série de reformas legislativas, incluindo a privatização, liberação dos preços e regulação do mercado. Em 1994 foi adotado o plano Real e aprovada a Lei $n^{\circ} 8.884 / 94$, denominada de Lei da Defesa da Concorrência.

A Lei da Concorrência promulgada na época, em 1994, logo ganhou reputação, e suas decisões refletiram-se na política da concorrência. Os procedimentos eram realizados por três instituições independentes, que coordenavam de forma pouco eficiente. Destaca-se que na época foi dada uma maior atenção aos atos de concentração, os quais não representavam uma grande ameaça à concorrência. Pouca atenção foi dada ao combate a cartéis, que consiste na conduta de maior impacto e no mercado ${ }^{4}$.

As deficiências supramencionadas foram corrigidas em 2010, através da modificação da legislação antitruste, incluindo o Brasil no rol internacional de combate ao cartel.

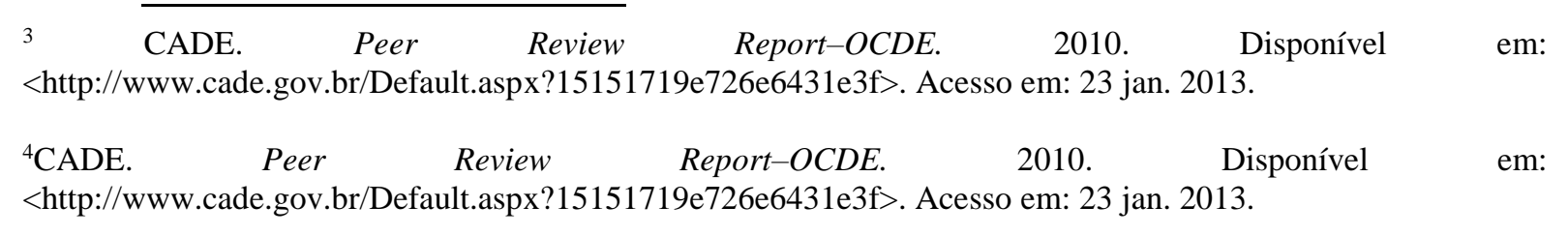


Com a entrada em vigor da nova Lei $\mathrm{n}^{\circ}$ 12.529/2011, foi reestruturado o SBDC na composição da política de defesa da concorrência, no rito do processo administrativo e na tipificação dos atos de infração contra a ordem econômica, entre outros aspectos ${ }^{5}$.

A tabela 1 faz uma síntese da evolução legal da matéria antitruste no Brasil, desde o Decreto-Lei de 18/11/1938, que estabeleceu na legislação pátria a repressão ao abuso do poder econômico, até a Lei n. 12.529/11, que é fruto de uma vasta evolução histórica e política do controle econômico.

\begin{tabular}{|c|c|c|c|c|}
\hline $\begin{array}{c}\text { BASE } \\
\text { CONSTITUCION } \\
\text { AL }\end{array}$ & LEGISLAÇÃO & DATA & EMENTA & OBSERVAÇÕES \\
\hline CF/1937, Art. 141 & $\begin{array}{l}\text { Decreto-Lei, n. } \\
869\end{array}$ & $18 / 11 / 1938$ & $\begin{array}{l}\text { Define os crimes contra a economia } \\
\text { popular, sua guarda e seu emprego. }\end{array}$ & $\begin{array}{l}\text { Nasceu para reprimir o } \\
\text { abuso do poder } \\
\text { econômico e proteger o } \\
\text { interesse do consumidor. }\end{array}$ \\
\hline CF 1937 & $\begin{array}{l}\text { Decreto-Lei n. } \\
\quad 7.666\end{array}$ & $22 / 06 / 1945$ & $\begin{array}{l}\text { Dispõe sobre atos contrários à } \\
\text { ordem moral e econômica. }\end{array}$ & $\begin{array}{lrr}\text { Conhecido } & \text { como } & \text { "Lei } \\
\text { Malária". } & \text { Cria } & \text { a } \\
\text { Comissão Administrativa } \\
\text { de Defesa } & \text { Econômica } \\
\text { (CADE). } & \end{array}$ \\
\hline $\mathrm{CF} / 1946$ & Lei n. 1.521 & $26 / 12 / 1951$ & $\begin{array}{l}\text { Altera dispositivos da legislação } \\
\text { vigente sobre crimes contra a } \\
\text { economia } \\
\text { popular. }\end{array}$ & $\begin{array}{l}\text { Conhecida como "Lei de } \\
\text { Economia Popular". } \\
\text { Contém dispositivos } \\
\text { antitruste. }\end{array}$ \\
\hline $\mathrm{CF} / 1946$ & Lei n. 1.522 & $26 / 12 / 1951$ & $\begin{array}{l}\text { Autoriza o Governo Federal a } \\
\text { intervir no domínio econômico para } \\
\text { assegurar a } \\
\text { livre distribuição de produtos } \\
\text { necessários ao consumo do povo. }\end{array}$ & $\begin{array}{l}\text { Contém dispositivos } \\
\text { antitruste. O órgão } \\
\text { executor da lei é a } \\
\text { Comissão Federal de } \\
\text { Abastecimento e Preços } \\
\text { (COFAP). }\end{array}$ \\
\hline CF/1946, Art. 148 & Lei n. 4.137 & $10 / 09 / 1962$ & $\begin{array}{l}\text { Regula a repressão ao abuso do } \\
\text { poder econômico. }\end{array}$ & $\begin{array}{l}\text { Criou o Conselho } \\
\text { Administrativo de } \\
\text { Defesa Econômica } \\
\text { (CADE). }\end{array}$ \\
\hline CF/1946, Art. 146 & $\begin{array}{l}\text { Lei Delegada } \\
\text { n. } 4\end{array}$ & $26 / 09 / 1962$ & $\begin{array}{l}\text { Dispõe sobre a intervenção no } \\
\text { Domínio econômico para assegurar } \\
\text { a livre distribuição de produtos } \\
\text { necessários ao } \\
\text { consumo do povo. }\end{array}$ & (2) \\
\hline CF/1946, Art. 146 & $\begin{array}{l}\text { Lei Delegada } \\
\text { n. } 5\end{array}$ & $26 / 09 / 1962$ & $\begin{array}{lcr}\text { Organiza a } & \text { Superintendência } \\
\text { Nacional do } & \text { Abastecimento } \\
\text { (SUNAB), e dá outras providências. }\end{array}$ & $\begin{array}{l}\text { Cria a SUNAB como } \\
\text { autarquia federal. }\end{array}$ \\
\hline $\mathrm{CF} / 1946$ & $\begin{array}{l}\text { Decreto-Lei } \\
\text { n. } 52.025\end{array}$ & $20 / 05 / 1963$ & $\begin{array}{l}\text { Aprova o regulamento da Lei } \mathrm{n}^{\circ} \\
4.137 \text {, de } 10 \text { de setembro de } 1962 \text {, } \\
\text { que regula a repressão ao abuso do } \\
\text { poder } \\
\text { econômico. }\end{array}$ & $\begin{array}{l}\text { Regulamenta a Lei } \mathrm{n}^{\circ} \\
4.137 .\end{array}$ \\
\hline CF/1967 & $\begin{array}{l}\text { Decreto } \mathrm{n} . \\
63.196\end{array}$ & $29 / 08 / 1968$ & $\begin{array}{l}\text { Dispõe sobre o sistema regulador de } \\
\text { preços no mercado interno e dá } \\
\text { outras }\end{array}$ & $\begin{array}{l}\text { Conselho Interministerial } \\
\text { de Preços (CIP). }\end{array}$ \\
\hline
\end{tabular}

${ }^{5}$ CARDOSO, Oscar Valente. A nova estrutura do CADE no Sistema Brasileiro de Defesa da Concorrência da Lei n. 12.529/11. Jus Navigandi. Teresina, ano, n. 3271, 15 jun. 2012. Disponível em: <http://jus.com.br/revista/texto/22026>. Acesso em: 14 jan. 2013. 


\begin{tabular}{|c|c|c|c|c|}
\hline & & & providências. & \\
\hline $\mathrm{EC} \mathrm{n}^{\circ} 1 / 1969$ & $\begin{array}{l}\text { Decreto-Lei } \\
\text { n. } 92.323\end{array}$ & 23/01/1986 & $\begin{array}{l}\text { Aprova o Regulamento da Lei } \mathrm{n}^{\circ} \\
4.137 \text {, de } 10 \text { de setembro de } 1962 \text {, } \\
\text { que disciplina a repressão ao abuso } \\
\text { do } \\
\text { poder econômico. }\end{array}$ & $\begin{array}{l}\text { Revoga DL } \mathrm{n}^{\circ} 52.025 \text { e } \\
\text { regulamenta a Lei } \mathrm{n}^{\circ} \\
4.137 \text {. }\end{array}$ \\
\hline CF/1988 & $\begin{array}{l}\text { Decreto } \\
\text { n. } 99.244\end{array}$ & $10 / 05 / 1990$ & $\begin{array}{l}\text { Dispõe sobre a reorganização e o } \\
\text { funcionamento dos órgãos da } \\
\text { Presidência da República e dos } \\
\begin{array}{l}\text { Ministérios, e dá outras } \\
\text { providências. }\end{array}\end{array}$ & $\begin{array}{l}\text { Cria a Secretaria } \\
\text { Nacional de Direito } \\
\text { Econômico (SNDE). }\end{array}$ \\
\hline CF/1988 & Lei n. 8.137 & 27/12/1990 & $\begin{array}{l}\text { Define crimes contra a ordem } \\
\text { tributária, econômica e contra as } \\
\text { relações de consumo, e dá outras } \\
\text { providências. }\end{array}$ & - \\
\hline CF/1988 & Lei n. 8.158 & 09/01/1991 & 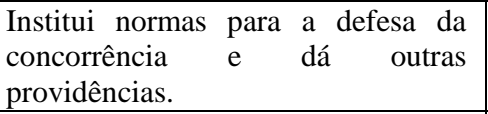 & - \\
\hline $\begin{array}{c}\text { CF/1988, Art. } 170 \mathrm{e} \\
173\end{array}$ & $\begin{array}{l}\text { Lei n. } 8.884 \\
\text { "Lei Antitruste" }\end{array}$ & 11/06/1994 & $\begin{array}{l}\text { Transforma o } \\
\text { Administrativo de } \\
\text { Econômica (CADE) em } \\
\text { Autarquia, dispõe sobre a prevenção } \\
\text { e a repressão às infrações contra a } \\
\text { ordem econômica e dá outras } \\
\text { providências. }\end{array}$ & $\begin{array}{l}\text { Configura o } \\
\text { Sistema Brasileiro de } \\
\text { Defesa da Concorrência } \\
\text { (SBDC), composto pela } \\
\text { Secretaria de } \\
\text { Acompanhamento } \\
\text { Econômico do Ministério } \\
\text { da Fazenda (SEAE), } \\
\text { Secretaria de Direito } \\
\text { Econômico do Ministério } \\
\text { da Justiça (SDE) e pelo } \\
\text { Conselho Administrativo } \\
\text { de Defesa Econômica } \\
\text { (CADE), autarquia } \\
\text { vinculada ao Ministério } \\
\text { da Justiça. }\end{array}$ \\
\hline CF/1988 & Lei n. 9.021 & 30/03/1995 & $\begin{array}{l}\text { Dispõe sobre a implementação da } \\
\text { autarquia Conselho Administrativo } \\
\text { de } \\
\text { Defesa Econômica (CADE), criada } \\
\text { pela Lei no } 8.884 \text {, de } 11 \text { de junho de } \\
\text { 1994, e dá outras providências. }\end{array}$ & $\begin{array}{l}\text { Permite que a SEAE } \\
\text { investigue possíveis } \\
\text { violações à lei de } \\
\text { concorrência. }\end{array}$ \\
\hline CF/1988 & Lei n. 9.069 & 29/06/1995 & $\begin{array}{l}\text { Dispõe sobre o Plano Real, o } \\
\text { Sistema Monetário Nacional, } \\
\text { estabelece as regras e condições de } \\
\text { emissão do } \\
\text { REAL e os critérios para conversão } \\
\text { das obrigações para o REAL, e dá } \\
\text { outras } \\
\text { providências. }\end{array}$ & Altera a Lei $n^{\circ} 8.884 / 94$ \\
\hline $\mathrm{CF} / 1988$ & Lei n. 9.069 & 29/06/1995 & $\begin{array}{l}\text { Dispõe sobre o Plano Real, o } \\
\text { Sistema Monetário Nacional, } \\
\text { estabelece as regras e condições de } \\
\text { emissão do } \\
\text { REAL e os critérios para conversão } \\
\text { das obrigações para o REAL, e dá } \\
\text { outras } \\
\text { providências. }\end{array}$ & Altera a Lei nº 8.884/94. \\
\hline $\mathrm{CF} / 1988$ & Lei n. 9.470 & 10/07/1997 & $\begin{array}{l}\text { Acrescenta parágrafo } 5^{\circ} \text { ao art. } 4^{\circ} \text { da } \\
\text { Lei } n^{\circ} 8.884 \text {, de } 11 \text { de junho de } \\
1994 \text {, e dá outras providencias. }\end{array}$ & - \\
\hline $\mathrm{CF} / 1988$ & Lei n. 10.149 & $21 / 12 / 2000$ & $\begin{array}{l}\text { Altera e acrescenta dispositivos à } \\
\text { Lei } \mathrm{n}^{\circ} 8.884 \text {, de } 11 \text { de junho de } \\
1994 \text {, que transforma o Conselho }\end{array}$ & $\begin{array}{l}\text { Cria programa de } \\
\text { leniência e aumenta } \\
\text { poderes de investigação }\end{array}$ \\
\hline
\end{tabular}




\begin{tabular}{|c|c|c|c|c|}
\hline & & & $\begin{array}{l}\text { Administrativo de } \\
\text { Econômica - CADE em autarquia, } \\
\text { dispõe sobre a prevenção e } \\
\text { repressão às infrações contra a } \\
\text { ordem econômica, e dá outras } \\
\text { providências. }\end{array}$ & da SDE e SEAE. \\
\hline CF/1988 & Lei n. $12.529 / 11$ & $30 / 11 / 2011$ & $\begin{array}{l}\text { Estrutura o Sistema Brasileiro de } \\
\text { Defesa da Concorrência; } \\
\text { dispõe sobre a prevenção e } \\
\text { repressão às infrações contra a } \\
\text { ordem econômica; e outras } \\
\text { providências. }\end{array}$ & $\begin{array}{l}\text { Amplia as competências } \\
\text { do CADE, altera os tipos } \\
\text { e valores das multas, } \\
\text { dentre outas mudanças. }\end{array}$ \\
\hline
\end{tabular}

Tabela 1: Legislação Antitruste no Brasil 6

Percebe-se, na Tabela 1, que a evolução da legislação antitruste transcorre simultânea e paralelamente ao crescimento do Estado liberal, atualmente globalizado e desenvolvido, na qual reflete, logicamente, no âmbito financeiro empresarial.

\section{A POLÍTICA ANTITRUSTE NO BRASIL}

\subsection{A Constituição e o Princípio da Livre Concorrência}

A Constituição Federal é o topo da pirâmide normativa brasileira e o fundamento de validade e orientação de todo o ordenamento pátrio.

A Carta Magna consagra, no Título VII: Da ordem econômica, em seu Capítulo I, os princípios gerais da atividade econômica, entre os quais ressalta, no artigo 170, inciso IV, o princípio da livre concorrência.

Acontece que essa livre iniciativa não representa uma liberdade total como aquela que marcou as ideias liberais de Adam Smith ${ }^{7}$, pois na mesma linha, a Carta Mãe dispõe que a lei reprimirá o abuso de poder econômico que vise à dominação dos mercados e à eliminação da ampla concorrência ${ }^{8}$.

\footnotetext{
${ }^{6}$ Homepages institucionais: $C A D E<$ http://www.cade.gov.br>, SDE/MJ <http://www.fazenda.gov.br/sde>, e SEAE/MF <http://www.fazenda.gov.br/seae>; Base de Dados do Senado Federal <http://wwwt.senado.gov.br/legbras>; Informações de Forgioni (1998) e Oliveira (1998).

${ }^{7}$ SALES, Fernando Augusto de Vita Borges de. Novos rumos do Direito Empresarial brasileiro: a Lei $n^{o}$ 12.529/2011 e a defesa da concorrência. Jus Navigandi, Teresina, ano 17, n. 3141, 6 fev. 2012. Disponível em: <http://jus.com.br/revista/texto/21030>. Acesso em: 7 fev. 2013.

${ }^{8}$ PAGANELLA, Marco Aurélio. A Constituição, o princípio da livre concorrência e o sistema de mercado dual ou misto. Jus Navigandi, Teresina, ano 9, n. 222, 15 fev. $2004 . \quad$ Disponível em: <http://jus.com.br/revista/texto/4823>. Acesso em: 7 fev. 2013.
} 
Neste esteio, a Constituição reconhece a existência do poder econômico. Este não é, pois, condenado pelo regime constitucional. Não raro esse poder econômico é exercido de maneira antissocial. Cabe, então, ao Estado coibir este abuso ${ }^{9}$.

Desta forma, a Lei 12.529/11 está amparada pela constitucionalidade por pleitear a defesa da ordem econômica, reprimindo infrações que atentem contra a liberdade de inciativa e a livre concorrência.

\subsection{A nova estrutura do CADE no SBDC}

A Lei n. 12.529/11 criou um novo sistema logístico para o SBDC. Tal sistema é composto pelo CADE e pela Secretaria de Acompanhamento Econômico do Ministério da Fazenda - SEAE, que funciona como órgão consultivo.

Após a aprovação da nova lei, verificou-se uma preocupação especial no combate aos cartéis. Dentre as mudanças, percebeu-se também que foram adotadas medidas para melhorar a alocação dos recursos disponíveis, acelerar e dar publicidade às investigações, como por exemplo, os acordos de cooperação com a Polícia Federal, celebração de acordos com Ministérios Públicos Federais e Estaduais, celebração de acordo com o Tribunal de Constas da União; criação do dia nacional de combate aos cartéis "8 de outubro", aumento das ações pedagógicas e acordos de cooperações com outros órgãos de controle, como por exemplo a Agência Nacional de Energia Elétrica-ANEEL e Agência Nacional de Aviação Civil ${ }^{10}$.

$\mathrm{O}$ artigo 36 da Lei 12.529/11 ${ }^{11}$ tipifica as condutas contrárias à ordem econômica, como se vê:

\footnotetext{
Art. 36. Constituem infração da ordem econômica, independentemente de culpa, os atos sob qualquer forma manifestados, que tenham por objeto ou possam produzir os seguintes efeitos, ainda que não sejam alcançados:

I - limitar, falsear ou de qualquer forma prejudicar a livre concorrência ou a livre iniciativa;

II - dominar mercado relevante de bens ou serviços;

III - aumentar arbitrariamente os lucros; e

IV - exercer de forma abusiva posição dominante.
}

\footnotetext{
${ }^{9}$ SILVA, José Afonso da. Curso de Direito Constitucional Positivo. 5 ed. São Paulo: Malheiros Editores, 1998. p. 876.

${ }^{10}$ Cartilha SDE sobre a Defesa da Concorrência no Judiciário. Coleção SDE/DPDE, 03/2009.

11 BRASIL. Lei n. 12.529, de 30 de novembro de 2011. Estrutura o Sistema Brasileiro de Defesa da Concorrência; dispõe sobre a repressão e prevenção às infrações contra a ordem econômica e altera legislações. Diário Oficial da União, Seção 1, Página 1.
} 
Pode-se citar como exemplo de conduta antitruste a adoção uniforme de preços, produção, comercialização e frequência de bens e serviços; divisão de mercados; limitação do acesso de novas empresas ao mercado; criação de dificuldade ao desenvolvimento de concorrente; combinação de preços; política comercial discriminatória, recusa de venda, dentre outras.

Com a passagem da vacatio legis ${ }^{12}$ da nova lei, advieram várias inovações que permitiram ao CADE reparar procedimentos que não eram totalmente eficazes, como por exemplo, a inspeção, que não carece mais de mandado judicial; a requisição de informações de quaisquer pessoas físicas ou jurídicas, autoridades e entidades públicas e privadas; a requisição de vista e cópia de processos judiciais, administrativos, inquéritos criminais.

No que tange as penalidades, houve uma relevante alteração, como mostra o quadro sinóptico, mostrado na Tabela 2.

Além das alterações nas penalidades existentes, também se criaram novas penalidades, como por exemplo, proibição de exercer o comércio em nome próprio ou como representante de pessoa jurídica pelo prazo de até cinco anos; multa de $\mathrm{R} \$ 1.000,00$ até $\mathrm{R} \$ 20.000,00$ por disseminação indevida de informações acerca de empresas por funcionários públicos ou prestadores de serviço do CADE /SEAE e multa de R 5.000,00 a R 5 milhões para falsificação de informações, documentos ou declarações prestadas ao CADE/SEAE.

\begin{tabular}{|c|c|c|}
\hline PENALIDADES & $\begin{array}{l}\text { LEI N. 8884/ } \\
\text { LEI N. } 8137\end{array}$ & LEI N. 12.529 \\
\hline $\begin{array}{c}\text { Para pessoas físicas ou jurídicas, de direito público ou } \\
\text { privado, bem como associações de entidades, ou pessoas } \\
\text { constituídas de fato ou de direito, com ou sem } \\
\text { personalidade jurídica, que não exerçam atividade } \\
\text { empresarial }\end{array}$ & $\begin{array}{l}\text { De } 6.000 \text { UFIR } \\
\text { a } 6.000 .000 \\
\text { Ufir }\end{array}$ & De $\mathrm{R} \$ 50.000$ a $\mathrm{R} \$ 2$ bilhões \\
\hline Para a empresa & $\begin{array}{l}\text { De } 1 \text { a } 30 \% \text { do } \\
\text { faturamento } \\
\text { bruto }\end{array}$ & $\begin{array}{l}\text { De } 0,1 \text { a } 20 \% \text { do faturamento } \\
\text { bruto restrito ao ramo de } \\
\text { atividade empresarial em que } \\
\text { ocorreu a infração }\end{array}$ \\
\hline Para os administradores direta ou indiretamente envolvidos & $\begin{array}{l}\text { De } 1 \text { a } 50 \% \text { da } \\
\text { multa aplicada } \\
\text { à empresa }\end{array}$ & $\begin{array}{l}\text { De } 1 \text { a } 20 \% \text { da multa aplicada } \\
\text { à } \\
\text { empresa, quando comprovada } \\
\text { culpa ou dolo }\end{array}$ \\
\hline Penalidades criminais & $\begin{array}{c}\text { Multa ou prisão } \\
\text { de } 2 \text { a } 5 \text { anos }\end{array}$ & Multa e prisão de 2 a 5 anos \\
\hline
\end{tabular}

\footnotetext{
${ }^{12}$ Espaço de tempo entre uma norma ser aprovada e entrar em vigor.
} 
Tabela 2: Comparação das penalidades entre a Lei n. 8.884/8.137 e a Lei n. 12.52913

Quando são analisados os precedentes do CADE, visualiza-se que o órgão vem, nos últimos anos, reafirmando seu espaço e autonomia no julgamento de condutas anticompetitivas, como mostra a Tabela 3.

\begin{tabular}{|c|c|}
\hline JULGAMENTOS ENCERRADOS & JULGAMENTOS EM ANDAMENTO \\
\hline $\begin{array}{l}\text { Cartel dos Gases Industriais (2010): condenação em R } \$ 2,3 \\
\text { bilhões }\end{array}$ & Programa Nacional de Dragagens \\
\hline União Brasileira de Avicultores (2010): TCC (R\$ 850 mil) & Mercado de leitores de discos ópticos (ODD). \\
\hline Frigoríficos (2009): TCC (R\$ 13,7 milhões) & $\begin{array}{l}\text { Mercado de produtos plásticos (ABS, PS, AS e } \\
\text { PMMA) }\end{array}$ \\
\hline $\begin{array}{l}\text { Mercado de areia lavada (2008): multas entre } 17.5 \% \text { e } \\
22.5 \% \text { do faturamento }\end{array}$ & Mercado de embalagens flexíveis; \\
\hline Cartel GLP (2008): multa de 1\% do faturamento & Mercado de cimento e concreto; \\
\hline $\begin{array}{l}\text { Vitaminas (2007): multas entre R\$ } 847 \text { mil e R\$ } 12.1 \\
\text { milhões }\end{array}$ & Mercado de Transporte de Cargas Aéreas; \\
\hline Britas (2005): multas entre $15 \%$ a $20 \%$ do faturamento & $\begin{array}{l}\text { ECAD (acusação de cartel e abuso de posição } \\
\text { dominante entre associações); }\end{array}$ \\
\hline $\begin{array}{c}\text { Revenda de Combustíveis em Florianópolis (2003): multa } \\
\text { de } \mathrm{R} \$ 55.000,00 \text { para o Sindicato }\end{array}$ & Monitores de LCD (acusação de cartel); \\
\hline Aço (1998): $1 \%$ do faturamento & $\begin{array}{l}\text { Suco de Laranja Concentrado e Congelado } \\
\text { (acusação de cartel); }\end{array}$ \\
\hline $\begin{array}{c}\text { Programa de exclusividade "Tô contigo" da AMBEV } \\
\text { (2009): condenação em R\$ } 325 \text { milhões }\end{array}$ & $\begin{array}{l}\text { Gasol/BR Distribuidora (acusação de abuso de } \\
\text { posição dominante); }\end{array}$ \\
\hline Rio Madeira (2007): TCC & Mercado de Cloro \\
\hline $\begin{array}{l}\text { Rede de Distribuidora Exclusiva da Microsoft (2004): } \\
\text { multas entre } 7 \% \text { a } 10 \% \text { do faturamento }\end{array}$ & Metrô de São Paulo \\
\hline- & $\begin{array}{c}\text { Transformadores (GIS, AIS e outros } \\
\text { equipamentos) }\end{array}$ \\
\hline
\end{tabular}

Tabela 3: Principais julgados do CADE finalizados e em andamento (2012) ${ }^{14}$

Por fim, resta mencionar que, de acordo com Monteiro ${ }^{15}$, a atuação do CADE apoia-se em três ações principais:

A atuação dos órgãos do sistema subdivide-se em três tipos: preventiva, através do controle de estruturas de mercado, via apreciação dos atos de concentração (fusões,

${ }^{13}$ ANDRADE, Maria Cecília. Controle das condutas na Lei n. 12.529/11, o que muda? 29 out. 2012. Disponível em:

<http://www.ibrac.org.br/Uploads/Eventos/5SeminarioBH/PALESTRAS/Maria\%20Cecilia\%20Andrade.pdf>. Acesso em: 04 fev. 2013.

${ }^{14}$ ANDRADE, Maria Cecília. Controle das condutas na Lei n. 12.529/11, o que muda? 29 out. 2012. Disponível em:

<http://www.ibrac.org.br/Uploads/Eventos/5SeminarioBH/PALESTRAS/Maria\%20Cecilia\%20Andrade.pdf>. Acesso em: 04 fev. 2013.

15 MONTEIRO, Carmen Diva. Sobre a política antitruste no Brasil e seus aspectos críticos. Dez. 2002. Disponível em: < http://www.seae.fazenda.gov.br/central_documentos/textos_artigos/2002-1/6antitrustpolicyininfrastructureservicesadevelopingcountryperspective>. Acesso em: 06. Jan. 2013. 


\begin{abstract}
aquisições e incorporações de empresas); repressiva, através do controle de condutas ou práticas anticoncorrenciais, que busca verificar a existência de infrações à ordem econômica, das quais são exemplos as vendas casadas, os acordos de exclusividade e a formação de cartel; e educacional, que corresponde ao papel de difusão da cultura da concorrência, via parceria com instituições para a realização de seminários, palestras, cursos e publicações de relatórios e matérias em revistas especializadas, visando um maior interesse acadêmico pela área, o incremento da qualidade técnica e da credibilidade das decisões emitidas e a consolidação das regras antitruste junto à sociedade.
\end{abstract}

Foram enviadas em média 4 mil cartilhas, versando a respeito do combate à prática de cartéis, para inúmeras associações e sindicatos do Brasil ${ }^{16}$.

\title{
3.3 A Defesa da Concorrência no Poder Judiciário
}

O Poder Judiciário e demais entes essenciais à administração da Justiça protagonizam papel fundamental para garantir a promoção da concorrência no Brasil. Desde as investigações de condutas anticompetitivas até as execuções das multas e das determinações do CADE, o Poder Judiciário está diretamente envolvido, e é crescente o número de casos judicializados ${ }^{17}$. Por exemplo, em 1995 houve apenas duas ações propostas contra decisões do CADE, em 2008, o número aumentou para 102 ações, já em 2012 a taxa de judicialização disparou para 166 demandas ${ }^{18}$.

Destarte, é necessário breve explanação a respeito da judicialização prematura da ação em trâmite no CADE. A ação judicial anterior ao julgamento do CADE retarda a apreciação da matéria pelo seu Plenário, o que compromete a efetividade do Tribunal no cumprimento de sua missão.

\section{CARTEL COMO A MAIS GRAVE LESÃO À CONCORRÊNCIA}

O cartel é tido como uma conduta praticada por particulares que se reúnem com o intuito de sustar a livre concorrência ou restringi-la e embaraçar a liberdade de escolha do consumidor, ocasionando um atraso no setor cartelizado, uma vez que não há concorrentes e a vontade de inovar torna-se cada vez mais imprópria, já que a presença de um mercado consumidor efetivo e presente garante os lucros desses empresários.

\footnotetext{
${ }^{16}$ Cartilha SDE sobre a Defesa da Concorrência no Judiciário. Coleção SDE/DPDE, 03/2009.

${ }^{17}$ Cartilha SDE sobre a Defesa da Concorrência no Judiciário. Coleção SDE/DPDE, 03/2009.

${ }^{18}$ CADE. Balanço Consolidado de 2012 apresentado na XXXIII Edição do PinCADE. Jan. 2013.
} 
Os cartéis constituem, assim, um dano não apenas para os adquirentes prejudicados, como também para a economia como um todo, porque a defesa da concorrência é matéria de direito público, uma vez que a lógica capitalista encontra uma de suas bases a disputa entre os agentes econômicos. ${ }^{19}$

No viés economicista, o cartel é definido como "um agrupamento de empresas que procura limitar a ação das forças da livre concorrência, para estabelecer um preço comum e/ou alcançar uma maximização conjunta dos $\operatorname{lucros}^{20}$.

De acordo com o Conselho Administrativo de Defesa Econômica - CADE, o cartel possui características favoráveis para sua dispersão que, segundo a Resolução n. 20/1999 ${ }^{21}$ do referido órgão, são:

Deve existir um alto grau de concentração de mercado, ou seja, um oligopólio; Seria inviável a formação de um cartel num universo de muitas empresas; Deve haver barreira à entrada de novos competidores, pois, se não há, ou se são de pequeno porte, outros concorrentes podem desestabilizar o conluio, frustrando os objetivos do cartel; Pressupostos inarredáveis também o são a homogeneidade de produtos e custos, bem como condições estáveis de custos e demanda.

Para que a conduta seja caracterizada como anticoncorrencial é necessário que haja uma grande concentração de empresas do ramo envolvidas no acordo e que este pacto traga impactos negativos ao mercado.

Araújo $^{22}$, durante o $2^{\circ}$ Encontro de Estratégia de Combate à Cartéis, relata algumas experiências das autoridades administrativas, das quais merecem atenção:

- A competição é saudável. Quando ela não existe, além do sobrepreço, causa prejuízo ao Estado;

- Cartel é crime desde 1990, com pena de 2 a 5 anos de reclusão, além da infração administrativa;

- A partir de 2003 passou-se a priorizar o combate a cartéis, havendo a aproximação ou parceria da esfera administrativa com a criminal;

19 TEIXEIRA, Osvaldo de Freitas. Cartel como forma de abuso do poder econômico. Jus Societas, v. 3, p. 83, n. 1, 2009. Disponível em: <http://revista.ulbrajp.edu.br/ojs/index.php/jussocietas/article/viewFile/15/453>. Acesso em 16 fev. 2013.

${ }^{20}$ MORCILLO, Francisco Morchón; TROSTER, Roberto Luís. Introdução à economia. São Paulo: Makroon Books, 1994, p. 161.

${ }^{21}$ BRASIL. Conselho Administrativo de Defesa Econômica-CADE. Resolução n. 20, de 9 de jun. de 1999. Dispõe, de forma complementar, sobre o processo administrativo. Disponível em: <http://www.cade.gov.br/upload/Resolu\%C3\%A7\%C3\%A3o\%20n\%C2\%BA\%2020,\%20de\%209\%20de\%20jun ho\%20de\%201999.pdf>. Acesso em: 16 fev. 2013.

22 ARAÚJO, Mariana Tavares de. Relatório do $2^{o}$ encontro de estratégia nacional de combate a cartéis. Suplemento eletrônico da Revista do IBRAC. Ano I, Número 4. Jun. 2010. Disponível em: <http://www.ibrac.org.br/Uploads/PDF/Suplemento\%20da\%20Revista\%20do\%20IBRAC\%20Ano\%201\%20n\% 204.pdf>. Acesso em: 16 fev. 2013. 
- Principal técnica investigativa de cartel é o acordo de leniência, espécie de delação premiada (delação concorrencial);

- O Brasil faz parte, há dez anos, de uma rede virtual de autoridades que defendem a concorrência, a International Competition Network - ICN. Uma pesquisa realizada com 46 países pela ICN demonstrou que há vários países que estão criminalizando a conduta do cartel e outros que estão com projetos de lei em andamento;

E continua:

- Multas aplicadas pela comissão europeia em quatro anos excederam a 9.75 bilhões de euros;

- Nos EUA alguns acordos de cartéis: $80 \%$ dos indivíduos investigados cumpriram pena privativa de liberdade em 2009 , multas criminais foram superiores a um milhão de reais por indivíduo em 2009;

- Registro de pelo menos 251 pessoas investigadas criminalmente no Brasil atualmente;

- O Brasil é considerado o país que mais avança no combate aos cartéis;

- O cartel é o mais grave ilícito concorrencial. Lesão direta aos consumidores;

- Furtar um real de um milhão de pessoas é tão grave quanto furtar um milhão de reais de uma só pessoa;

No Brasil, no plano internacional, a partir da nova lei, têm-se combatido fortemente as condutas anticoncorrenciais e o acordo de leniência, espécie de delação premiada, que será esmiuçada posteriormente.

\section{COMBATE A CARTÉIS: PRIORIDADE ABSOLUTA}

As atividades do CADE resumem-se em duas: controle de estruturas (preventivo), para analisar atos de concentração e controle de condutas (repressivo), para reprimir condutas anticompetitivas, da qual se inclui o combate ao cartel. A tipificação legal está disposta nos artigos 4 e 36, parágrafo 3, inciso I e II, da Lei n. 12.529/11.

O cartel é um acordo explícito ou implícito entre concorrentes para fixação de preços ou quotas de produção, divisão de clientes e de mercados de atuação. Cartéis são considerados a mais grave lesão à concorrência porque prejudicam seriamente os consumidores ao aumentar preços e restringir a oferta, tornando os bens e serviços mais caros ou indisponíveis.

Ao limitar a concorrência, os membros de um cartel também prejudicam a inovação, impedindo que novos produtos e processos produtivos surjam no mercado. Cartéis resultam em perda de bem-estar do consumidor e, no longo prazo, perda de competitividade da economia como um todo. Segundo estimativas da organização para a Cooperação e Desenvolvimento Econômico - OCDE, os cartéis geram um sobrepreço estimado entre 10 e 
$20 \%$ comparado ao preço em um mercado competitivo, causando prejuízos de centenas de bilhões de reais aos consumidores anualmente ${ }^{23}$.

As provas no cartel podem ser diretas e indiretas. As provas diretas são quaisquer evidências que demonstrem a existência de acordo formal entre os concorrentes, tais como: escutas telefônicas, atas de assembleia ou reunião, declaração de participante acerca de participação a respeito de acordo ou reunião sobre ocorrência de cartel, e-mails trocados entre concorrentes, mensagens de texto de celulares, etc. Contudo, as provas indiretas são quaisquer evidências que contrariem a ordem normal de um mercado, cuja explicação não pode ser outra a não ser a de um cartel, tais como: aumento de preço verificado em curto espaço de tempo ou logo após reunião entre concorrentes, padrões suspeitos em licitações, etc.

As sanções aplicadas a empresas ou grupos de empresas condenadas com tal prática são multas de $0,1 \%$ a $20 \%$ do faturamento bruto da empresa, do grupo ou do conglomerado no ramo de atividade empresarial da infração no ano anterior ao do início do processo; a multa para as pessoas físicas (administrador), condenado por culpa ou dolo, é de 10 a $20 \%$ da aplicada a empresa e demais pessoas físicas, jurídicas, entes despersonalizados, associações e sindicatos, que não exerçam atividade empresarial e não possuem faturamento, a multa é de 50 mil a 2 bilhões de reais. Além da proibição de contratar com instituições financeiras oficiais e de participar de licitações por no mínimo cinco anos, cisão da sociedade, transferência de controle, venda de ativos ou cessação parcial de atividades, proibição de exercer comércio em nome próprio ou como representante de pessoa jurídica por até 5 anos, entre qualquer outra medida que seja necessária para a eliminação dos efeitos nocivos à concorrência ${ }^{24}$.

Acerca da classificação do cartel, a doutrina elenca algumas espécies, tais como os cartéis hard-core ${ }^{25}$, cartéis clássicos ou institucionalizados, cartéis soft-core ${ }^{26}$, cartéis difusos ou não institucionalizados, influência em conduta uniforme, auxílio/convite a cartelizar, cartéis em licitações, cartéis em sindicatos e associações, em revenda de combustíveis, dentre outras.

A seguir, estudar-se-ão algumas espécies de cartéis.

\footnotetext{
${ }^{23}$ Cartilha SDE sobre o Combate aos cartéis em licitações. Coleção SDE/DPDE, 03/2009.

${ }^{24}$ Cartilha SDE sobre o Combate aos cartéis em licitações. Coleção SDE/DPDE, 03/2009.

${ }^{25}$ Cartéis intrinsicamente nocivos à ordem econômica.

${ }^{26}$ Cartéis difusos ou não institucionalizados.
} 


\subsection{Cartéis em Licitações}

As licitações são um ambiente propício à atuação dos cartéis, que podem agir de várias formas, como por exemplo, fixando preços entre concorrentes com a finalidade de que as propostas fiquem abaixo de um preço-base, definindo quem irá vencer determinados certames ou uma série de processos licitatórios, dividindo um conjunto de licitações entre membros do cartel, suprimindo propostas, apresentando propostas com valores altos ou com objetivo de direcionar a licitação para um concorrente especial, fazendo rodízio de entre os vencedores de uma licitação específica e subcontratando os participantes desistentes pelo participante vencedor.

Em muitos cartéis, mais de uma dessas formas de atuar podem estar presentes, para dar a impressão de efetiva concorrência. De qualquer forma, o resultado é sempre o aumento dos preços pagos pela Administração Pública e a consequente transferência ilegítima de recursos para os membros do cartel ${ }^{27}$.

Neste contexto, o CADE, através da Superintendência-Geral, informou no dia 14 de fevereiro de 2013, a abertura de um processo administrativo para investigar suspeita de cartel em licitações feitas por órgãos públicos no Distrito Federal para contratação de serviço terceirizado na área de tecnologia da informação $-\mathrm{TI}^{28}$. Ressalta-se a condenação de outros casos de cartéis em licitações, como por exemplo, o caso Rio Madeira, o cartel das britas e o cartel dos vigilantes.

\subsection{Cartéis em Sindicatos e Associações de Classe}

Os sindicatos e associações podem representar membros de uma ou mais indústrias. Estes órgãos são de fundamental importância para o desenvolvimento da economia, pois permitem o debate de temas de interesse coletivo, como por exemplo, preocupações ambientais e trabalhistas.

Por vezes, contudo, os sindicatos e associações de classe extrapolam suas funções institucionais e acabam por coordenar e/ou influenciar acordos entre seus associados no

\footnotetext{
${ }^{27}$ Cartilha SDE sobre o Combate aos cartéis em licitações. Coleção SDE/DPDE, 03/2009.

${ }^{28}$ AMATO, Fábio. CADE investiga suposto cartel em licitação para serviço de TI. G1 Economia e Negócios. 14 fev. 2013. Disponível em: <http://g1.globo.com/economia/negocios/noticia/2013/02/cade-investiga-supostocartel-em-licitacao-para-servico-de-ti.html>. Acesso em: 16 fev. 2013.
} 
sentido de uniformizar condutas comerciais. Os maiores riscos de violação á Lei de Defesa da Concorrência estão naquelas entidades que congregam concorrentes como seus associados ${ }^{29}$.

Ilícitos concorrenciais ocorrem quando os sindicatos e associações se tornam fóruns para que concorrentes mantenham acordos ou troquem informações sobre preços, clientes, áreas de atuação, forma de venda, planos de negócio e participação em licitações. Além disso, sindicatos e associações podem contribuir com mecanismos de auditoria e monitoramento do cumprimento do acordo. Tais práticas infringem a lei antitruste pátria e prejudicam gravemente o consumidor.

Dentre os julgados do CADE, relata-se as seguintes condenações da prática de cartel: o caso do Sindicato da Indústria de Mineração de Pedra Britada do Estado de São Paulo SINDIPEDRAS e o cartel das britas, a Associação dos Portos de Areia do Noroeste do Paraná - APA e o cartel da areia (em trâmite), a Associação das Autoescolas de Campinas, o caso do SINDICAVIR, a Associação dos Tradutores e o caso da Associação Brasileira das Agências de Viagem.

\subsection{Cartéis na Revenda de Combustíveis}

Até o início da década de 90, o mercado de revenda de derivados do petróleo encontrava fortes restrições. A rígida regulamentação na época inibia a entrada de novos investidores nesses setores. Diante desta situação, em 1990, o Governo Federal diminuiu gradativamente o controle sobre estas atividades. Em 2001 a comercialização foi totalmente liberada e, com a economia de mercado, os empresários puderam estipular seus preços de acordo com seus custos e suas estratégias de vendas ${ }^{30}$.

O mercado de combustíveis possui as seguintes características: homogeneidade do produto com relativa diferenciação locacional e de marca, presença de barreiras à entrada de novos ofertantes, inexistência de bens substitutos próximos, existência de demanda atomizada, painéis com os preços na entrada do estabelecimento e a atuação ativa por parte de sindicatos.

Analisando-as, percebe-se que tais características facilitam a formação de cartel, acarretando em homogeneidade de preços e prejudicando, consequentemente, os consumidores.

${ }^{29}$ Cartilha SDE sobre o Combate a carteis em sindicatos e associações. Coleção SDE/DPDE, 03/2009.

${ }^{30}$ Cartilha SDE sobre o Combate a carteis em sindicatos e associações. Coleção SDE/DPDE, 03/2009. 
Madruga $^{31}$, durante o $2^{\circ}$ Encontro de Estratégia de Combate a Carteis, explora ainda mais o setor de combustíveis, examinando os procedimentos investigatórios, como se percebe:

- CARTEL: descobrir se há acordo ou não, no setor de combustíveis, preços iguais ou parecidos não são indícios, por si só, de existência de cartel, pois decorrem das características deste mercado; pulverização de agentes, produto homogêneo, transparência de preços e custos semelhantes. É o que se dá, principalmente, em pequenas cidades, isso dificulta a deteç̧ão de existência de cartel;

- Limite investigativo da SDE (atualmente incorporado ao CADE): lei 8.884/94: SDE possui poderes para utilizar as seguintes ferramentas de investigação para detectar cartéis: (1) programa de leniência; (2) busca e apreensão, via AGU mas, como se disse, no setor de combustíveis não basta a existência de preços iguais; (3) inspeção (empresa deve ser notificada com 24h de antecedência); (4) tomada de depoimentos; (5) encaminhamento de ofícios para requisitar documentos e informações;

- Histórico de condenações do CADE: 2004 - Revenda de combustíveis de Recife (PE), aplicação de multa; 2003 - Revenda de combustíveis de Florianópolis (SC), foi utilizada interceptação telefônica, comprovando o ajuste, aplicação de multa;

Tratando dos meios de provas que determinaram as condenações, da dificuldade de investigação e das limitações legais das autoridades administrativas, o Dr. Madruga continua:

- Provas consideradas pelo CADE: (1) Recife: atas do sindicato; (2) Lages: interceptação telefônica; (3) Belo Horizonte: gravação audiovisual de reunião no sindicato, eles não sabiam que a imprensa estava lá e ajustaram a reunião para tratar de preço; (4) Goiânia: termo de depoimento do presidente do sindicato; (5) Florianópolis: interceptação telefônica;

- De dois anos pra cá se tornou mais difícil administrativamente se investigar os cartéis. As pessoas não estão mais colocando no papel (nas atas de reunião), de modo que se faz necessário adotar medidas invasivas da privacidade, a exemplo da interceptação telefônica e ambiental, para se detectar os cartéis: João Pessoa (2008) - STJ anulou a interceptação telefônica; Londrina (2010); Belo Horizonte (2010); Cuiabá (pendente de decisão judicial); Caxias do Sul (aguardando provas - interceptação); Vitória 9juiz não deferiu compartilhamento de provas com a SDE - interceptação);

- Limitações legais das autoridades administrativas para produção de provas (não podem interceptar, por exemplo); investigação criminal cada vez mais necessária para que haja repressão por parte das autoridades administrativas. Os cartelistas estão em constante evolução, sempre buscando técnicas novas para ajustar os preços e evitar a ação das autoridades.

A mera análise dos preços é, por si só, superficial, não sendo suficiente para a instauração de um processo administrativo. A investigação deve ser aprofundada para que seja obtida um mister de provas que comprovem a combinação de preços.

31 MADRUGA, Ravvi Augusto de Abeu C.. Relatório do $2^{o}$ encontro de estratégia nacional de combate a cartéis. Suplemento eletrônico da Revista do IBRAC. Ano I, Número 4. Jun. 2010. Disponível em: <http://www.ibrac.org.br/Uploads/PDF/Suplemento\%20da\%20Revista\%20do\%20IBRAC\%20Ano\%201\%20n\% 204.pdf>. Acesso em: 16 fev. 2013. 


\subsection{Programa de Leniência}

Dada à dificuldade de investigação das condutas cartelistas, como já foi mencionada anteriormente, a cooperação dos participantes do ato anticoncorrencial facilita a condenação das demais. Por esse motivo, países tais como África, Alemanha, Japão, Portugal, União Europeia e o Brasil adotam o programa de leniência.

O programa foi introduzido na Lei de Defesa da Concorrência, em 2000. E o CADE é o órgão demarcado para negociar e conceder o acordo de leniência. O artigo 86 da Lei antitruste vigente permite ao CADE fechar acordos com pessoas físicas e jurídicas.

O primeiro caso intercorreu à Secretaria de Defesa Econômica - SDE (atualmente integrado ao CADE), em 2003, após a abertura de investigação a uma comunidade empresarial. Até o ano de 2012, 33 acordos de leniência foram celebrados, além das solicitações em andamento ${ }^{32}$. A tabela 4 expõe a quantidade de acordos de leniência/ano.

Presente na atual legislação antitruste, a Lei n. 12.529/11 reconhece que é do interesse dos cidadãos brasileiros conceder benefícios para aquele participante que queira por fim na conduta e cooperar de forma plena com as autoridades, de modo a permitir a condenação dos demais participantes do cartel. Acentua-se que o interesse em punir todas as empresas/indivíduos participantes do cartel é maior do que a extinção da punibilidade de um único participante ${ }^{33}$.

\begin{tabular}{|c|c|}
\hline ANO & QUANTIDADE DE ACORDOS FECHADOS \\
\hline 2003 & 1 \\
\hline 2004 & 1 \\
\hline 2005 & 1 \\
\hline 2006 & 4 \\
\hline 2007 & 1 \\
\hline 2008 & 2 \\
\hline 2009 & 4 \\
\hline 2010 & 8 \\
\hline 2011 & 1 \\
\hline 2012 & 12 \\
\hline TOTAL & $33^{*}$ \\
\hline
\end{tabular}

32 BRASIL. Conselho Administrativo de Defesa Econômica - CADE. Programa de Intercâmbio do CADE PinCADE. Palestra: Nova lei de defesa da concorrência brasileira. Jan. 2013. Disponível em: <http://www.cade.gov.br:8080/pincade/includes/conteudo/Arquivos/bibliobasica/Apresentacao_PinCADE_Ticia na.pdf>. Acesso em: 17 fev. 2013.

33 Cartilha SDE sobre o Combate a cartéis e programas de leniência. Coleção SDE/DPDE, 03/2009. 
Tabela 4: Acordos de leniência celebrados pelo CADE por ano ${ }^{34}$

* Além dos acordos em andamento.

\section{6 À GUISA DE CONCLUSÃO}

O Brasil possui um rico e peculiar histórico da política concorrencial. Os avanços na legislação pátria são conhecidos no âmbito internacional como uma das mais complexas e avançadas entre as demais e o Departamento de Justiça dos Estados Unidos afirmou que o Brasil é o país que mais tem se destacado nos últimos anos ${ }^{35}$.

A Lei Antitruste brasileira, Lei n. 12.529/11, está amparada pela constitucionalidade, por pleitear a defesa da ordem econômica, reprimindo infrações que atentem contra a liberdade de inciativa e a livre concorrência.

O Sistema Brasileiro de Defesa Econômica é composto pela Comissão Administrativa de Defesa Econômica e a Secretaria de Acompanhamento Econômico - SEAE do Ministério da Fazenda.

A atuação positiva do CADE no combate a condutas anticompetitivas é confirmada nesse trabalho, através da elucidação dos procedimentos, objetivos da autarquia, jurisprudências e números crescentes de processos julgados com êxito.

O poder de um cartel de restringir a concorrência traz prejuízos também á inovação, por impedir que outros concorrentes aprimorem seus processos evolutivos e lancem novos e melhores produtos no mercado. O Brasil, desde 2003, considera o combate a cartéis uma prioridade absoluta.

Neste sentido, propõe-se, neste trabalho que a prioridade dada atualmente ao cartel deva ser mantida e ampliada, pois na era capitalista em que se vive, a busca por lucros, através de preços exorbitantes e dominação de mercados, é curso habitual da comunidade empresarial.

\section{REFERÊNCIAS}

\subsection{REFERENCIAS BIBLIOGRAFICAS}

\footnotetext{
${ }^{34}$ BRASIL. Conselho Administrativo de Defesa Econômica - CADE. Programa de Intercâmbio do CADE PinCADE. Palestra: Nova lei de defesa da concorrência brasileira. Jan. 2013. Disponível em: <http://www.cade.gov.br:8080/pincade/includes/conteudo/Arquivos/bibliobasica/Apresentacao_PinCADE_Ticia na.pdf>. Acesso em: 17 fev. 2013.

${ }^{35}$ Cartilha SDE sobre o Combate a cartéis e programas de leniência. Coleção SDE/DPDE, 03/2009.
} 
AMATO, Fábio. Cade investiga suposto cartel em licitação para serviço de TI. G1 Economia e Negócios. 14 fev. 2013. Disponível em:

<http://g1.globo.com/economia/negocios/noticia/2013/02/cade-investiga-suposto-cartel-emlicitacao-para-servico-de-ti.html>. Acesso em: 16 fev. 2013.

ANDRADE, Maria Cecília. Controle das condutas na Lei $n$. 12.529/11, o que muda? 29 out. 2012. Disponível em:

<http://www.ibrac.org.br/Uploads/Eventos/5SeminarioBH/PALESTRAS/Maria\%20Cecilia\% 20Andrade.pdf>. Acesso em: 04 fev. 2013.

ARAÚJO, Mariana Tavares de. Relatório do $2^{\circ}$ encontro de estratégia nacional de combate a cartéis. Suplemento eletrônico da Revista do IBRAC. Ano I, Número 4. Jun. 2010.

Disponível em:

<http://www.ibrac.org.br/Uploads/PDF/Suplemento\%20da\%20Revista\%20do\%20IBRAC\%2 0Ano\%201\%20n\%204.pdf >. Acesso em: 16 fev. 2013.

BRASIL. Conselho Administrativo de Defesa Econômica - CADE. Programa de Intercâmbio do CADE - PinCADE. Palestra: Nova lei de defesa da concorrência brasileira. Jan. 2013. Disponível em:

<http://www.cade.gov.br:8080/pincade/includes/conteudo/Arquivos/bibliobasica/Apresentaca o_PinCADE_Ticiana.pdf $>$. Acesso em: $17 \mathrm{fev} .2013$.

Conselho Administrativo de Defesa Econômica-CADE. Resolução n. 20, de 9 de jun. de 1999. Dispõe, de forma complementar, sobre o processo administrativo. Disponível em:

<http://www.cade.gov.br/upload/Resolu\%C3\%A7\%C3\%A3o\%20n\%C2\%BA\%2020,\%20de \%209\%20de\%20junho\%20de\%201999.pdf>. Acesso em: 16 fev. 2013.

Lei n. 12.529, de 30 de novembro de 2011. Estrutura o Sistema Brasileiro de Defesa da Concorrência; dispõe sobre a repressão e prevenção às infrações contra a ordem econômica e altera legislações. Diário Oficial da União, Seção 1, Página 1. Jan. 2013.

CADE. Balanço Consolidado de 2012 apresentado na XXXIII Edição do PinCADE.

CADE. Peer Review Report-OCDE. 2010. Disponível em:

<http://www.cade.gov.br/Default.aspx?15151719e726e6431e3f>. Acesso em: 23 jan. 2013.

CARDOSO, Oscar Valente. A nova estrutura do CADE no Sistema Brasileiro de Defesa da Concorrência da Lei n. 12.529/11. Jus Navigandi. Teresina, ano 17, n. 3271, 15 jun. 2012.

Cartilha SDE sobre a Defesa da Concorrência no Judiciário. Coleção SDE/DPDE, 03/2009.

Cartilha SDE sobre o Combate a cartéis e programas de leniência. Coleção SDE/DPDE, 03/2009. 
Cartilha SDE sobre o Combate a cartéis em sindicatos e associações. Coleção SDE/DPDE, 03/2009.

Cartilha SDE sobre o Combate aos cartéis em licitações. Coleção SDE/DPDE, 03/2009.

Homepages institucionais: $C A D E<$ http://www.cade.gov.br>, SDE/MJ

$<$ http://www.fazenda.gov.br/sde>, e

SEAE/MF <http://www.fazenda.gov.br/seae>; Base de Dados do Senado Federal. Disponível em: <http://wwwt.senado.gov.br/legbras>; Informações de Forgioni (1998) e Oliveira (1998).

MADRUGA, Ravvi Augusto de Abeu C.. Relatório do $2^{\circ}$ encontro de estratégia nacional de combate a cartéis. Suplemento eletrônico da Revista do IBRAC. Ano I, Número 4. Jun. 2010. Disponível em:

<http://www.ibrac.org.br/Uploads/PDF/Suplemento\%20da\%20Revista\%20do\%20IBRAC\%2 0Ano\%201\%20n\%204.pdf>. Acesso em: 16 fev. 2013.

MONTEIRO, Carmen Diva. Sobre a política antitruste no Brasil e seus aspectos críticos. Dez. 2002. Disponível em: <

http://www.seae.fazenda.gov.br/central_documentos/textos_artigos/2002-1/6antitrustpolicyininfrastructureservicesadevelopingcountryperspective >. Acesso em: 06. Jan. 2013.

MORCILLO, Francisco Morchón; TROSTER, Roberto Luís. Introdução à economia. São Paulo: Makroon Books, 1994, p. 161.

PAGANELLA, Marco Aurélio. A Constituição, o princípio da livre concorrência e o sistema de mercado dual ou misto. Jus Navigandi, Teresina, ano 9, n. 222, 15 fev. 2004. Disponível em: <http://jus.com.br/revista/texto/4823>. Acesso em: 7 fev. 2013.

SALES, Fernando Augusto de Vita Borges de. Novos rumos do Direito Empresarial brasileiro: a Lei $\mathrm{n}^{\circ} 12.529 / 2011$ e a defesa da concorrência. Jus Navigandi, Teresina, ano 17, n. 3141, 6 fev. 2012. Disponível em: <http://jus.com.br/revista/texto/21030>. Acesso em: 7 fev. 2013.

SEAE/MF <http://www.fazenda.gov.br/seae>; Base de Dados do Senado Federal SILVA, José Afonso da. Curso de Direito Constitucional Positivo. 5 ed. São Paulo: Malheiros Editores, 1998. P. 876.

TEIXEIRA, Osvaldo de Freitas. Cartel como forma de abuso do poder econômico. Jus Societas, v. 3, p. 83, n. 1, 2009. Disponível em: <http://revista.ulbrajp.edu.br/ojs/index.php/jussocietas/article/viewFile/15/453>. Acesso em 16 fev. 2013.

\subsection{BIBLIOGRAFIA CONSULTADA:}


CUSTÓDIO, Antonio Joaquim Ferreira. Concentração econômica. O artigo 54 da Lei Antitruste e a Constituição Federal. Jus Navigandi, Teresina, ano 13, n. 1890, 3 set. 2008. Disponível em: <http://jus.com.br/revista/texto/11673>. Acesso em: 18 fev. 2013.

FREITAS, Grabriela Oliveira. A livre concorrência e os ilícitos concorrenciais. Disponível em:

<http://www.ambitojuridico.com.br/site/index.php?n_link=revista_artigos_leitura\&artigo_id= 6977>. Acesso em: 17 jan. 2013.

LARA, Alexandre. Defesa da concorrência: análise de mercado, práticas desleais e posição dominante. Disponível em: <http://www.ebah.com.br/content/ABAAAAMKAAI/defesaconcorrencia-analise-mercado-praticas-desleais-posicao-dominante>. Acesso em: 18 jan. 2013.

MARTINS, Amanda Athayde Linhares. Prova indireta de cartel no âmbito das associações: comportamento paralelo consciente e plus factors. Disponível em:

$<$ http://portalrevistas.ucb.br/index.php/EALR/article/viewFile/3/Prova\%20indireta\%20de\%20 cartel\%20no\%20\%C3\%A2mbito\%20das\%20associa\%C3\%A7\%C3\%B5es\%3A\%20comporta mento\%20paralelo\%20e\%20plus\%20factors>. Acesso em: 17 jan. 2013.

MECELIS, Adriana. A proteção da ordem econômica e a defesa da concorrência. Aspectos históricos, constitucionais e legais da atuação do CADE. Jus Navigandi, Teresina, ano 16, n. 2924, 4 jul. 2011. Disponível em: <http://jus.com.br/revista/texto/19470〉. Acesso em: 18 fev. 2013.

. Atuação do CADE na Defesa da Concorrência - LEI $n^{\circ}$ 8.884/93. Portal Jurídico Investidura, Florianópolis/SC, 08 Jun. 2011. Disponível em: <www.investidura.com.br/biblioteca-juridica/artigos/direito-administrativo/186351>. Acesso em: 18 Fev. 2013.

PAGANELLA, Marco Aurélio. A Constituição, o princípio da livre concorrência e o sistema de mercado dual ou misto. Jus Navigandi, Teresina, ano 9, n. 222, 15 fev. 2004. Disponível em: <http://jus.com.br/revista/texto/4823>. Acesso em: 18 fev. 2013.

PANIZZA, Nathalia Brito. A nova lei do Sistema Brasileiro de Defesa da Concorrência: principais alterações concernentes ao CADE. Disponível em:

$<$ http://conteudojuridico.com.br/artigo,a-nova-lei-do-sistema-brasileiro-de-defesa-daconcorrencia-principais-alteracoes-concernentes-ao-cade,37095.html >. Acesso em: 18 jan. 2013.

RIZZO, Guilherme Franzen. A nova Lei de Defesa da Concorrência brasileira - Lei $n^{o}$ 12.529/11 . Jus Navigandi, Teresina, ano 16, n. 3094, 21 dez. 2011 . Disponível em: <http://jus.com.br/revista/texto/20688>. Acesso em: 18 fev. 2013. 